\title{
Performance Evaluation of Hot Mix Asphalt with Different Proportions of RAP Content
}

\author{
Ahmad Kamil Arshad ${ }^{1, *}$, Haryati Awang ${ }^{1}$, Ekarizan Shaffie ${ }^{2}$, Wardati Hashim², and \\ Zanariah Abd Rahman ${ }^{2}$ \\ ${ }^{1}$ Institute for Infrastructure Engineering and Sustainability Management (IIESM)/Faculty of Civil \\ Engineering, University Teknologi MARA, Shah Alam, Selangor, Malaysia \\ ${ }^{2}$ Faculty of Civil Engineering, Universiti Teknologi MARA, Shah Alam, Selangor, Malaysia
}

\begin{abstract}
Reclaimed Asphalt Pavement (RAP) is old asphalt pavement that has been removed from a road by milling or full depth removal. The use of RAP in hot mix asphalt (HMA) eliminates the need to dispose old asphalt pavements and conserves asphalt binders and aggregates, resulting in significant cost savings and benefits to society. This paper presents a study on HMA with different RAP proportions carried out to evaluate the volumetric properties and performance of asphalt mixes containing different proportions of RAP. Marshall Mix Design Method was used to produce control mix ( $0 \%$ RAP) and asphalt mixes containing 15\% RAP, $25 \%$ RAP and 35\% RAP in accordance with Specifications for Road Works of Public Works Department, Malaysia for AC14 dense graded asphalt gradation. Volumetric analysis was performed to ensure that the result is compliance with specification requirements. The resilient modulus test was performed to measure the stiffness of the mixes while the Modified Lottman test was conducted to evaluate the moisture susceptibility of these mixes. The Hamburg wheel tracking test was used to evaluate the rutting performance of these mixes. The results obtained showed that there were no substantial difference in Marshall Properties, moisture susceptibility, resilient modulus and rutting resistance between asphalt mixes with RAP and the control mix. The test results indicated that recycled mixes performed as good as the performance of conventional HMA in terms of moisture susceptibility and resilient modulus. It is recommended that further research be carried out for asphalt mixes containing more than $35 \%$ RAP material.
\end{abstract}

\section{Introduction}

A pavement which deteriorates gives poor riding quality, reduce vehicle traction due to lack of surface friction and increase vehicle users' maintenance costs. Timely maintenance is required to maintain the pavement at a certain desirable condition. Pavement recycling can be combined with other preventive pavement maintenance treatments to provide a long lasting pavement that performs at a high level of serviceability [1]. Pavement recycling

* Corresponding author: drahmadkamil@,salam.uitm.edu.my 
involves the reuse of reclaimed asphalt material (RAP) obtained from deteriorated roads by milling or ripping/crushing operation. There are several advantages in reusing RAP as pavement materials in terms of environmental, economic and engineering perspectives. The primary environmental advantages include conservation of resources and saving landfill space. It is also economical as the material cost is reduced when RAP is used in HMA [2][3].

In the United States, approximately about $80 \%$ of asphalt pavement removed during highway rehabilitation or reconstruction is recycled back into new hot mix asphalt (HMA), disposing of only $20 \%$ through normal waste stream channels [4]. These materials still possess desirable properties to be used for the surfacing layers, subject to the limitations set in the specification used. In the hot mix recycling process, RAP material is combined with new aggregate and asphalt binder or recycling agent in a hot mix plant. With proper materials evaluation and mix design, similar or better performance can be achieved for hot mix asphalt combined with RAP compared to mixtures made with virgin materials. However, although recycling is beneficial in reducing the consumption of virgin materials, the performance of the highway pavement should not be compromised for cost reduction [5]. It has been accepted that RAP can be a feasible constituent in HMA pavements and if properly designed and constructed, HMA mixtures with RAP can perform as well as conventional mixtures [6].

Studies in Europe and the United States have concluded that over $80 \%$ of the recycled material is reused in the construction of roads, but regulations are still strict in allowing the inclusion of RAP in proportions ranging between 5 and $50 \%$ for the production of new HMA mixtures [7]. Some studies indicate that incorporating low percentages of RAP (up to $15 \%$ RAP) have no significant changes in the performances of mixes [8][9]. Previous researchers also stated that RAP replacement at proportions below $50 \%$ is feasible to produce new HMA mixtures, obtaining satisfactory results in the mechanical properties. In addition, RAP replacement at proportions above $50 \%$ is feasible to produce new HMA mixtures, obtaining satisfactory results in the mechanical properties [10][11]. Partial blending of RAP binder occurs in the hot mix asphalt when RAP is mixed with virgin mineral materials and virgin binder. The amount of RAP has been limited to certain portions because the degree of blending between the RAP and the virgin materials is not known. If the weight by percent of all materials and their recycling technology are properly selected, the composition and properties of RAP HMA are improved.

Little research has been carried out on mixes containing RAP exceeding $25 \%$ as higher amount of RAP produced variability in Marshall Properties and performance of HMA. The objective of this study is to evaluate the performance of HMA mixtures with variable RAP content $(15 \%, 25 \%$ and $35 \%$ RAP), in particular the Marshall properties and performance in terms of resilient modulus, moisture susceptibility and rutting resistance.

\section{Methodology}

This study is based on laboratory experimental work. The samples were prepared using the Marshall Test method in accordance with ASTM D1559. The mix design used AC14 aggregate gradation in accordance with PWD Malaysia's Specification for Road Works [12], with the range of binder content from $4.0 \%$ to $6.0 \%$. A total of 15 samples were prepared for the control mix (100\% virgin aggregates) and the asphaltic concrete mixes with RAP contents of $15 \%, 25 \%$ and $35 \%$. All the samples were compacted with 75 blows on both sides of the samples using Marshall Compactor. Volumetric properties and analysis were carried out to determine the optimum binder content (OBC) for control mix and recycled mix. The optimum bitumen content value was used for the performance tests, including resilient modulus, moisture susceptibility and rutting. The Modified Lottman test 
was performed to evaluate the moisture susceptibility of the mixes in accordance with the procedure described in AASHTO T 283. Samples for the test were prepared at $7+0.5$ percent air voids. The resilient modulus test was performed in accordance with ASTM D 4132. Testing temperatures of 25 and $35^{\circ} \mathrm{C}$ were used and loading of $1300 \mathrm{~N}$ with a load pulse of 0.1 seconds and rest period of 0.9 seconds were set. The Hamburg Wheel Tracking test was carried out in accordance with AASHTO T324 to evaluate the rutting susceptibility of mixtures under high temperature. The equipment used for this test was the Asphalt Pavement Analyzer (APA) that is capable of running Hamburg Wheel Tracking tests. The test was run at a rate of 50 passes of a steel wheel per minute with a load of $705+22 \mathrm{~N}$. This test was conducted until the maximum number of 8,000 passes has occurred or until the maximum rut depth value of $20 \mathrm{~mm}$ has been reached.

\section{Results and discussions}

The initial laboratory tests have been conducted to determine physical properties of the materials used. The Marshall mix design was conducted to determine the marshall properties and the optimum binder content (OBC) for control mix and rap-asphalt mixes. The results of the moisture susceptibility test, resilient modulus and rutting test as performance tests were then compared between the control mix and RAP-Asphalt mixes.

\subsection{Comparison of RAP aggregate and virgin aggregate properties.}

RAP aggregate properties assist in evaluating the suitability of the aggregates to be used in road construction. The basic properties tests that were conducted for both virgin and RAP aggregates consist of Los Angeles abrasion test, aggregate impact test and specific gravity. The detailed test results for both types of aggregate are shown in Table 1.

In this study, based on the results as shown in Table 1, the LAAV, AIV, Specific Gravity for RAP aggregate is higher than virgin aggregate. This indicates that the strength of the recycled aggregate is lower than virgin aggregate. However, the value complied with PWD Malaysia's specification requirements which must not exceed $25 \%$ for LAAV and AIV. This is due to the fact that the recycled aggregate was exposed to traffic loading for a long period that reduced the strength of aggregate, unlike the virgin aggregate which has not been exposed to traffic. Since both types of aggregate complied with the specification requirements, the aggregate is suitable to be used in the asphalt mixture preparation.

Table 1. Basic properties of Virgin Aggregate and RAP Aggregate.

\begin{tabular}{|c|c|c|c|}
\hline Parameter & $\begin{array}{c}\text { Virgin } \\
\text { Aggregate }\end{array}$ & $\begin{array}{c}\text { Reclaimed } \\
\text { Asphalt } \\
\text { Aggregate } \\
\text { (RAP) }\end{array}$ & $\begin{array}{c}\text { PWD } \\
\text { Malaysia's } \\
\text { Specification } \\
\text { requirement }\end{array}$ \\
\hline Los Angeles Abrasion Value (\%) & 24.00 & 24.91 & $<25$ \\
\hline Aggregate Impact Value (\%) & 14.99 & 19.98 & $<25$ \\
\hline Bulk Specific Gravity, Gsb $\left(\mathrm{g} / \mathrm{cm}^{3}\right)$ & 2.648 & 2.625 & - \\
\hline Apparent Specific Gravity $\left(\mathrm{g} / \mathrm{cm}^{3}\right)$ & 2.705 & 2.711 & - \\
\hline Water Absorption $(\%)$ & 0.626 & 1.063 & $<2.0$ \\
\hline
\end{tabular}




\subsection{Marshall properties}

Marshall Test was conducted to determine the volumetric properties of the mixture. The volumetric properties determined included bulk specific gravity, air void, voids in the mix (VMA), stability and flow. The Optimum Binder Content (OBC) for the control and RAPAsphalt mixes were determined from the individual plots of bulk density, voids in the total mix, voids in the mix, flow and stability versus percent asphalt content.

Mix properties of virgin materials and varying different percentage of RAP showed that there is a significant effect on the Marshall Properties with the inclusion of RAP in the asphalt mixes. Marshall Test results showed that the Marshall flow, VFB and Bulk SG increased as the RAP content increased. However, Marshall Stability value and voids in mix showed a decreasing trend with increasing RAP content. The trends are shown in Fig. 1 to Fig. 5 below. This result could be attributed to the fact that the virgin bitumen failed to rejuvenate the RAP binder as its percentage increases. However, the results and analysis showed that there is not much variation between conventional mixes with RAP-Asphalt mixes and all the mixes satisfy the requirements of the Specifications for Marshall Test.

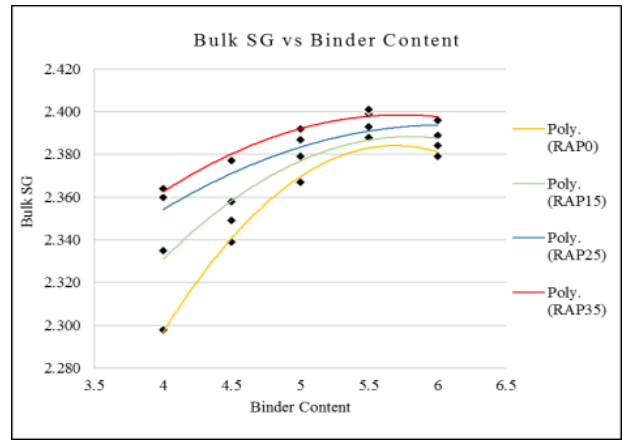

Fig. 1. Bulk Specific Gravity versus Binder Content for Different RAP Contents.

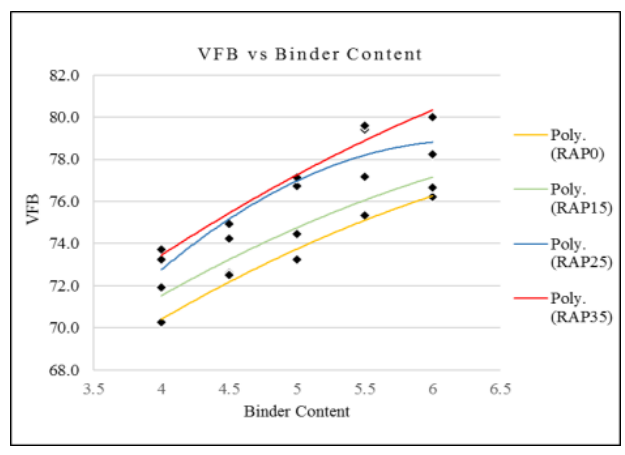

Fig. 3. VFB versus Binder Content for Different RAP Contents.

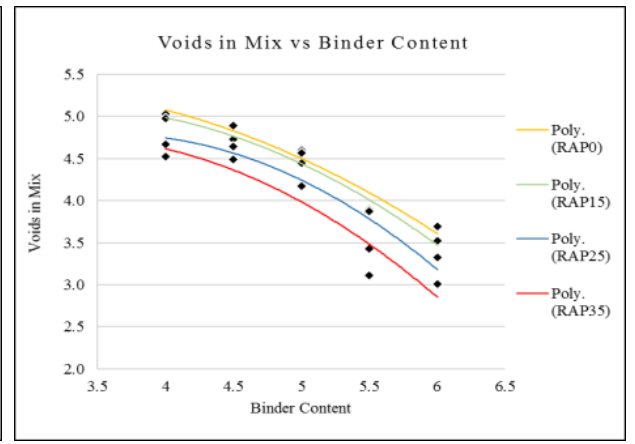

Fig. 2. Voids in Mix versus Binder Content for Different RAP Contents.

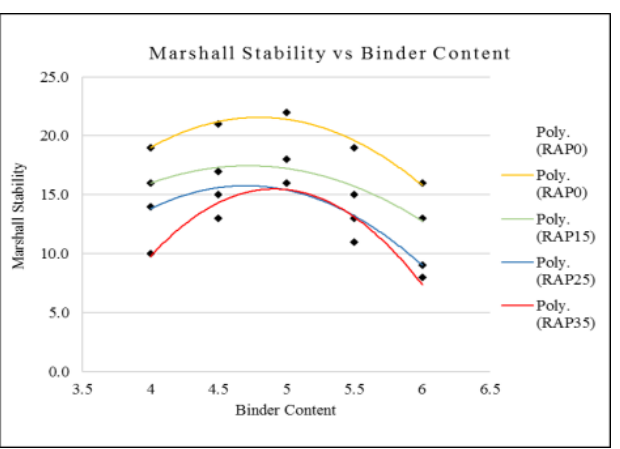

Fig. 4. Marshall Stability versus Binder Content for Different RAP Contents. 


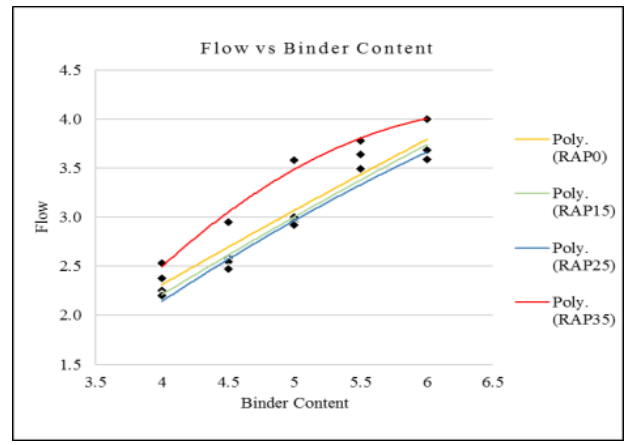

Fig. 5. Flow versus Binder Content for Different RAP Contents.

\subsection{Marshall properties and determination of optimum binder content}

The OBC for control mix and RAP-Asphalt mixes were taken as the arithmetic mean of binder from the five smooth curves plotted and the value was checked with the limits set by the Public Works Department of Malaysia specification. Table 2 showed the Optimum Binder Content $(\mathrm{OBC})$ for the control and RAP-Asphalt mixes. The OBC decreased as the RAP content increased. The OBC for control mix, RAP15 and RAP25 and RAP35 are 5.34 $\%, 5.22 \%, 5.10 \%$ and $4.88 \%$ respectively. The result obtained showed that there were no substantial differences in Marshall Properties. However, the lower values of OBC with increasing RAP content indicates the possibility that the existing binder in the RAP interacts with the virgin binder and therefore lowered the $\mathrm{OBC}$ value.

Table 2. Mix Design selection Criteria.

\begin{tabular}{|c|c|c|c|c|c|}
\hline Properties & $\begin{array}{c}\text { Control } \\
\text { Mix }\end{array}$ & RAP15 & RAP25 & RAP35 & $\begin{array}{c}\text { PWD } \\
\text { Specification }\end{array}$ \\
\hline OBC (\%) & 5.34 & 5.22 & 5.10 & 4.88 & - \\
\hline Bulk S.G & 2.388 & 2.393 & 2.399 & 2.401 & - \\
\hline VIM (\%) & 4 & 4 & 4 & 4 & $3-5$ \\
\hline VFB (\%) & 75.33 & 75.20 & 75.20 & 75.10 & $70-80$ \\
\hline Stability (kN) & 22 & 18 & 16 & 18 & $>8$ \\
\hline Flow (mm) & 3 & 2.95 & 2.92 & 2.95 & $2-4$ \\
\hline
\end{tabular}

\subsection{Moisture Susceptibility}

The results of indirect tensile strength (ITS) for control mix and RAP-Asphalt mixes are shown in Fig. 6. It could be seen that the increase of RAP in the asphalt mix reduces the tensile strength values compared with the control mix. The results show that the ITS values of wet condition and dry condition decreased with increasing RAP content. The values of Control Sample, RAP15, RAP25 and RAP35 reduced by $4.29 \%, 12.16 \%, 16.13 \%$, and $20.0 \%$ respectively, after the wet conditioning process. The highest value of ITS in dry condition is $0.74 \mathrm{MPa}$ for RAP15 and $0.67 \mathrm{MPa}$ in wet condition for control sample. 


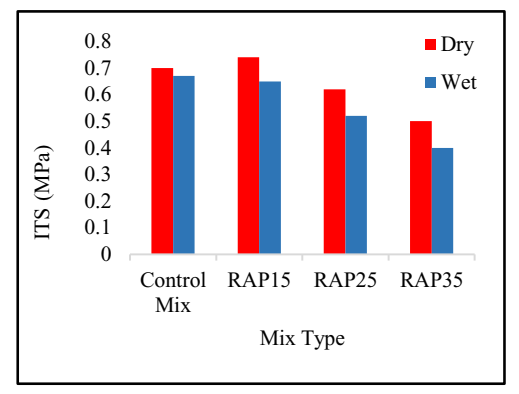

Fig. 6. Indirect Tensile Strength (ITS) for Variable RAP Content.

The Tensile Strength Ratio (TSR) values for control mix and RAP-Asphalt mixes are shown in Fig. 7. From the results, it shows that the TSR values decreased with increasing of RAP content. The highest TSR value is $95.96 \%$ for Control mix while the lowest TSR value is $80.14 \%$ for RAP35. The results indicate that Control Mix to be less susceptible to moisture damage compared to RAP-Asphalt mixes. However, all the mixes have the potential to resist moisture damage since the TSR values obtained are more than $80 \%$.

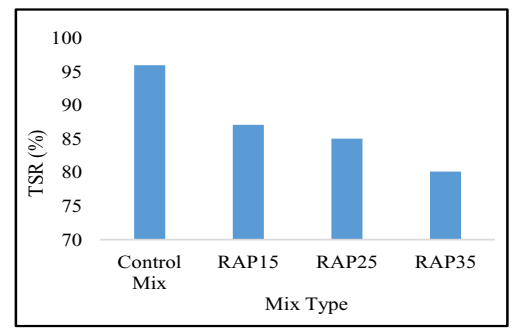

Fig. 7. Tensile Strength Ratio (TSR) for variable RAP Content.

\subsection{Resilient Modulus of RAP Mixtures}

The results of the resilient modulus test for control mix and RAP-Asphalt mixes at temperatures of $25^{\circ} \mathrm{C}$ and $35^{\circ} \mathrm{C}$ are shown in Fig. 8. The resilient modulus for all mixes at temperature $25^{\circ} \mathrm{C}$ is higher for all mixes than at temperature of $35^{\circ} \mathrm{C}$. The control sample has the highest resilient modulus under both testing temperatures compared to RAP-Asphalt mixes. The resilient modulus of control sample at temperatures of $25{ }^{\circ} \mathrm{C}$ and $35{ }^{\circ} \mathrm{C}$ are $3953 \mathrm{MPa}$ and $2842 \mathrm{MPa}$ respectively. This is followed by RAP15 with values of 3784 $\mathrm{MPa}$ and $1991 \mathrm{MPa}$ at temperatures of $25^{\circ} \mathrm{C}$ and $35^{\circ} \mathrm{C}$ respectively. RAP25 and RAP35 have lower resilient modulus values compared to RAP15. The results showed that the resilient modulus of the mixes decreases with increasing RAP content. This decrease in resilient modulus value may possibly be due to the effect of the existing binder in the RAP which decreases the stiffness of the mixes.

\subsection{Rutting Resistance of RAP Mixtures}

The result of the rutting test for control mix and RAP-Asphalt mixes is shown in Figure 9. The rut depth increased with the increase in the RAP content of the asphalt mix. The control sample exhibit the highest resistance to rutting compared to RAP-Asphalt mixes with a depth of $3.4 \mathrm{~mm}$ at 8000 wheel passes. RAP15 reached a rut depth of $3.7 \mathrm{~mm}$ at 8000 wheel passes, followed by RAP25 and RAP35 with rut depths of $4.2 \mathrm{~mm}$ and $4.4 \mathrm{~mm}$ 
respectively. The higher rut depth indicates that the mixes with higher RAP content have lower resistance to rutting. This increase in rut depth may possibly be due to the effect of the existing binder in the RAP which increases the deformation of the mix and increases the rut depth.

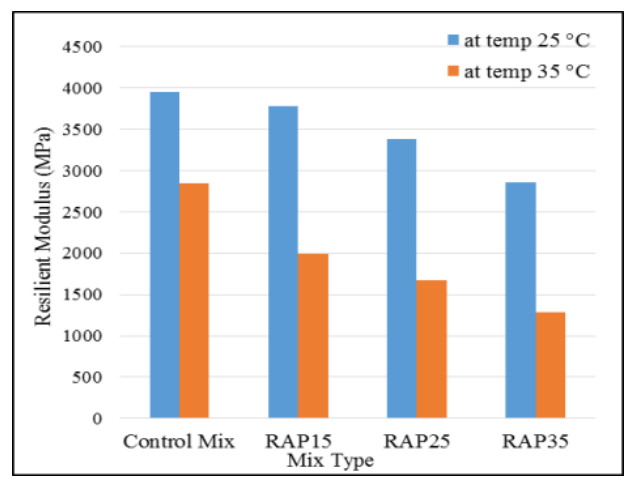

Fig. 8. Resilient Modulus for Variable RAP Content at Temperature of $25^{\circ} \mathrm{C}$ and $35^{\circ} \mathrm{C}$.

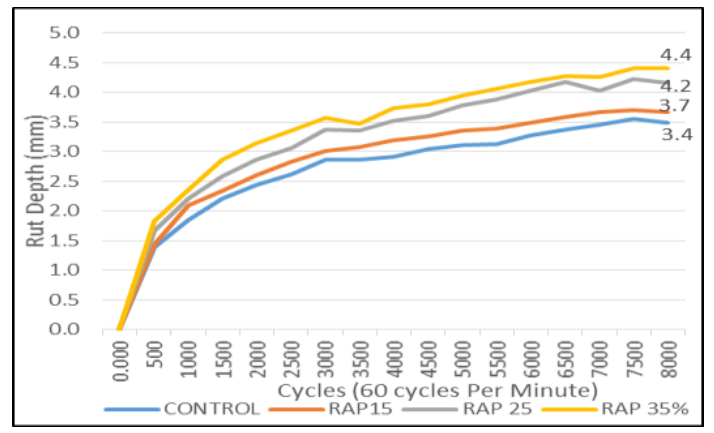

Fig. 9. Rut depth for Hamburg wheel tracking test for different RAP content.

\section{Conclusions}

From this study, the following can be concluded:

i. The laboratory results on the physical properties of virgin aggregate and RAP shows that the aggregates used in this study complied with the requirements in the Public Works Department specifications. The recovered aggregate from RAP has lower strength compared to virgin aggregate. This is due to the RAP material which is exposed to the environment and traffic for a certain period of time.

ii. The OBC of control mix, RAP15, RAP25 and RAP35 showed a decreasing trend with increasing RAP content. The OBC of control mix, RAP15, RAP25 and RAP35 are $5.34 \%, 5.22 \%, 5.10 \%$ and $4.8 \%$ respectively. This indicates that there was partial blending of aged binder from RAP, but the effect is not as significant for low percentages of RAP in the mixes.

iii. Dry and wet ITS tests were performed to evaluate the moisture susceptibility performance of recycled mixes. The ITS and TSR value of the mixture decreases as the RAP content increases under both conditions. RAP-Asphalt mixtures satisfied the minimum required value for the moisture susceptibility test. 
iv. The resilient modulus of the RAP-Asphalt mixtures decreased with increasing RAP content and temperature.

v. The Hamburg wheel tracking test showed that the rutting resistance also decreased when the RAP content increased. However, the difference in rut depth between the control sample and RAP mixes is minimal, indicating that the mixes with RAP have comparable rut resistance compared to control mix.

Based on the findings of the study, it can be concluded that it is possible to design acceptable quality asphaltic concrete mixes with RAP that meets the required volumetric and desired performance criteria. As the performance of RAP mixes satisfied the minimum requirements of PWD Malaysia, the use of recycled mixes should be encouraged as the use of RAP likely to be cheaper than normal mix. The results of this study indicate that the addition of RAP to HMA is feasible as the performance is comparable to conventional asphaltic concrete mixes. The use of higher percentages of RAP content requires a detailed study and investigation to be carried out to ensure the RAP suitability and compliance with the specification requirements.

The authors would like to express gratitude to the Institute for Engineering and Sustainability Management (IIESM) and The Ministry of Higher Education, Malaysia for the financial support through the FRGS Research Grant: FRGS/1/2015/TK08/UITM/02/3.

\section{References}

1. Asphalt Recycling and Reclaiming Association, Basic Asphalt Recycling Manual, ARRA, Annapolis, (2001)

2. K. Kuehl, J. Korzilius, M. Marti, Synthesis of Recycled Asphalt Pavement (RAP) Material, Minnesota Department of Transportation, St. Paul, (2016)

3. A.M. Abu Abdo, Int. J. Thermal \& Env. Eng. 12, 61-66 (2016)

4. A. Carter, Development of A Non-Solvent Based Test Method for Evaluating Reclaimed Asphalt Pavement Mixes, PhD Thesis, Auburn University, Alabama, USA, (2004)

5. L. Mohammad, I. Negulescu, Z. Wu, C. Daranga, W. Daly, J. Assoc.Asphalt Pav. Tech. 72, 551-594 (2003)

6. B. Huang, X. Shu, D. Vukosavljevic, ASCE J. of Mat. in Civil Eng. 23, 1535-1543 (2011)

7. W. Mengqi, W. Haifang, W. Muhunthan, N. Kalehiwot, N., Proc. of the 91st Trans. Res. Board Mtg. Transportation Research Board, Washington D.C., (2012)

8. H.R. Paul, Proc. of The Assoc. of Asphalt Paving Tech. 65, 231-254 (1996)

9. Austroads, Maximising the Re-use of Reclaimed Asphalt Pavement (Field Validation), Austroads Ltd, Sydney, (2016)

10. R. West, J.R. Willis, M. Marasteanu, Improved Mix Design, Evaluation, and Materials Management Practices for Hot Mix Asphalt with High Reclaimed Asphalt Pavement Content, Transportation Research Board, Washington D.C. (2013)

11. K. Vislavicius, H. Sivilevicius, J. of Civil and Mech. Eng. (2013)

12. Public Works Department of Malaysia, Standard Specification For Road Works Section 4: Flexible Pavement (JKR/SPJ/2008-S4), PWD Malaysia, Kuala Lumpur, (2008) 